\title{
Intracellular and extracellular magnesium depletion in Type 2 (non-insulin-dependent) diabetes mellitus
}

\author{
L. M. Resnick ${ }^{1}$, B.T. Altura ${ }^{2}$, R. K. Gupta ${ }^{3}$, J.H. Laragh ${ }^{1}$, M.H. Alderman ${ }^{3}$, B.M. Altura ${ }^{2}$ \\ ${ }^{1}$ Cardiovascular Center, New York Hospital-Cornell Medical Center, New York, New York, USA \\ ${ }^{2}$ Department of Physiology, State University of New York, Brooklyn, New York, USA \\ ${ }^{3}$ Departments of Epidemiology, Physiology and Biophysics, Albert Einstein College of Medicine, Bronx, New York, USA
}

\begin{abstract}
Summary. To investigate alterations of magnesium metabolism in Type 2 (non-insulin-dependent) diabetes mellitus, we utilized a new magnesium-specific selective ion electrode apparatus to measure serum ionized magnesium (Mg-io) in fasting subjects with and without Type 2 diabetes, and compared these values to levels of serum total magnesium, and of intracellular free magnesium (Mgi) analysed by ${ }^{31} \mathrm{P}-\mathrm{NMR}$ spectroscopy. Both Mg-io $(0.630 \pm 0.008$ vs $0.552 \pm$ $0.008 \mathrm{mmol} / \mathrm{l}, \quad p<0.001)$ and $\mathrm{Mgi}(223.3 \pm 8.3$ vs $184 \pm$ $13.7 \mathrm{mmol} / 1, p<0.001$ ), but not serum total magnesium, were significantly reduced in Type 2 diabetes compared with nondiabetic control subjects. Furthermore, a close relationship was observed between serum Mg-io and Mgi $(r=0.728$,
\end{abstract}

$p<0.001$ ). We suggest that magnesium deficiency, both extracellular and intracellular, is a characteristic of chronic stable mild Type 2 diabetes, and as such, may predispose to the excess cardiovascular morbidity of the diabetic state. Furthermore, by more adequately reflecting cellular magnesium metabolism than total serum magnesium levels, $\mathrm{Mg}$-io measurements may provide a more readily available tool than has heretofore been available to analyse magnesium metabolism in a variety of diseases.

Key words: Magnesium, nuclear magnetic resonance spectroscopy, Type 2 (non-insulin-dependent) diabetes mellitus, erythrocytes, ion selective electrode.
Although the cellular physiology of magnesium metabolism is still poorly understood, it has long been observed that insulin stimulates cellular magnesium uptake [1]. Accordingly, in acute diabetic ketoacidosis consequent to insulin deficiency, considerable total body deficits of magnesium routinely occur $[2,3]$. However, it is unclear whether chronic stable diabetes, especially Type 2 (noninsulin-dependent) diabetes mellitus, is also a state of magnesium depletion [4-6]. This is a clinically relevant question, since magnesium deficiencies have been implicated in the pathogenesis of hypertension, atherosclerosis, and cardiac arrhythmias, all present to an increased extent in subjects with chronic Type 2 diabetes [7-10].

The assessment of magnesium status has been difficult, due largely to a lack of adequate technologies for measuring magnesium. Indeed, spontaneous hypomagnesaemia is an uncommon finding in subjects with diabetic or vascular syndromes. Our group has recently utilized non-invasive nuclear magnetic resonance (NMR) techniques to study intracellular free magnesium concentrations (Mgi), and have reported consistent significant reductions of free magnesium in erythrocytes from fasting Type 2 diabetic subjects [11], in non-diabetic essential hypertensive subjects [12], and in relation to the degree of insulin resistance present [13]. To complement these studies, and to design easier, more clinically applicable techniques, we have employed a new ion-specific magnesium electrode apparatus to measure extracellular, serum ionized magnesium levels [14].

The present study, based on the above newer techniques, and reported in abstract form previously [15], suggests the presence of both cellular and circulating magnesium depletion in mild, diet-controlled Type 2 diabetes. We believe these findings have both pathophysiologic as well as therapeutic implications in diabetes generally, and reinforce the link between altered glucose and divalent cation metabolism [16].

\section{Subjects and methods}

Subjects arrived at the Cardiovascular Center of the New York Hospital-Cornell Medical Center after an overnight fast, and had venous blood drawn while in the seated position. None of the subjects were receiving medication for any current medical condition, or had been on antidiabetic therapy. Type 2 diabetes $(n=22)$ was diagnosed on the basis of fasting whole blood glucose values greater than $7.8 \mathrm{mmol} / \mathrm{l}(140 \mathrm{mg} \%)$ and elevated $\mathrm{HbA}_{1 \mathrm{c}}$ levels, both on at least two consecutive occasions at least one month apart. Non-diabetic 
Table 1. Extracellular and intracellular free magnesium levels in normal and Type 2 diabetic subjects

\begin{tabular}{llll}
\hline & $\begin{array}{l}\mathrm{Mg-t} \\
(\mathrm{mmol} / \mathrm{l})\end{array}$ & $\begin{array}{l}\mathrm{Mg} \text {-io } \\
(\mathrm{mmol} / \mathrm{l})\end{array}$ & $\begin{array}{l}\mathrm{Mgi} \\
(\mathrm{mmol} / \mathrm{l})\end{array}$ \\
\hline Control subjects & 0.86 & 0.630 & 223.3 \\
$(n=30)$ & \pm 0.01 & \pm 0.008 & \pm 8.3 \\
Type 2 diabetes & 0.81 & $0.552^{\mathrm{a}}$ & $184.1^{\mathrm{a}}$ \\
$(n=22)$ & \pm 0.05 & \pm 0.008 & \pm 13.7 \\
\hline
\end{tabular}

${ }^{a} p<0.001$ vs control subjects

$\mathrm{Mg}-\mathrm{t}$, Serum total magnesium; $\mathrm{Mg}$-io, serum ionized magnesium; Mgi, intracellular free magnesium

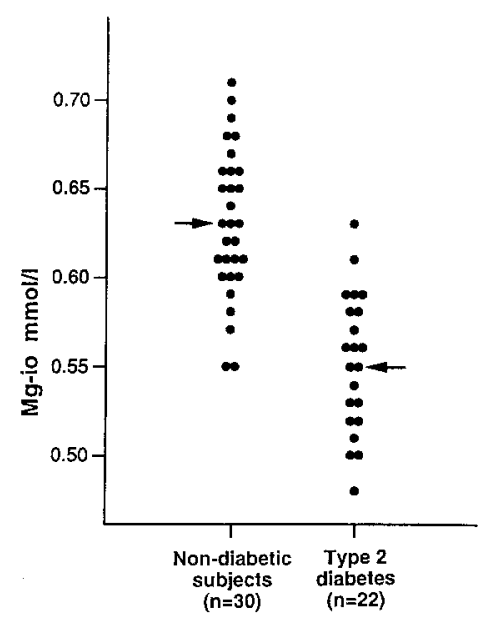

Fig. 1. Distribution of serum ionized magnesium (Mg-io) values in normal and diabetic subjects. Arrows indicate average values in non-diabetic $(0.630 \pm 0.008 \mathrm{mmol} / \mathrm{l})$ compared to Type 2 diabetic subjects $(0.552 \pm 0.008 \mathrm{mmol} / \mathrm{l})$ which were significantly different, $(p<0.001)$

control subjects $(n=30)$ were obtained from among a population of healthy individuals followed-up prospectively to study the incidence of cardiovascular disease in a general population (NIH-SCOR). Non-diabetic individuals were matched for age, sex, and race with the diabetic subjects.

Blood obtained from these subjects was analysed for serum total magnesium, serum ionized magnesium ( $\mathrm{Mg}$-io), and for erythrocyte intracellular free magnesium (Mgi). All blood samples were obtained anaerobically through vacuum needle extraction. Serum total magnesium was analysed using standard Autoanalyzer techniques. Serum ionized magnesium (Mg-io) was analysed using blood drawn into air-evacuated glass tubes containing an inert cell-separating gel matrix. After clotting and centrifugation, the tube was inverted, and the serum drawn off under vacuum into a syringe, which was then capped and sent for analysis. Serum $\mathrm{Mg}$-io was determined using a magnesium ion-selective electrode (ISE) containing a neutral carrier-based membrane, which provides measurement values within $2 \mathrm{~min}$. This new ISE for ionized magnesium has been recently characterized, and $\mathrm{Mg}$-io values obtained by this technique from whole blood, serum, and plasma are virtually identical [14]. Using this technique, venous $\mathrm{pH}$ values in these samples from both patient groups were within the published range of normal, and did not significantly differ from each other.

Erythrocyte intracellular free magnesium (Mgi) was measured by ${ }^{31} \mathrm{P}-\mathrm{NMR}$ spectroscopic techniques, the details of which have been previously described [12]. Briefly, heparinized blood is centifuged, and the packed cells decanted into $10 \mathrm{~mm}$, thin-walled NMR tubes, which are then placed in the NMR spectrometer for analysis. All spectra were obtained on a Varian XL 200 spectrometer, operating at $37^{\circ} \mathrm{C}$. Mgi levels were determined according to the formula [17],

$\mathrm{Mgi}=\mathrm{K}_{\mathrm{d}}(\mathrm{Mg} \mathrm{ATP})\left\{\Phi^{-1}-1\right\}$

where $\Phi$ is the free, unbound fraction of ATP, calculated from the chemical shift differences of the alpha and beta phosphoryl resonances of ATP on the ${ }^{31} \mathrm{P}-\mathrm{NMR}$ spectrum, and $\mathrm{K}_{\mathrm{d}}(\mathrm{MgATP})$ is $38 \mathrm{mmol} / \mathrm{l}$ at $37^{\circ} \mathrm{C}$.

\section{Statistical analyses}

The various magnesium values were compared betweed Type 2 diabetic and control subjects using standard unpaired Student's $t$-tests. Relations between $\mathrm{Mg}$-io and $\mathrm{Mgi}$ values were analysed using linear regression analysis and Pearson correlation coefficients. All values are reported as mean \pm SEM.

\section{Results}

There were no significant demographic distinctions between the Type 2 diabetic $(n=22)$ and control, nondiabetic $(n=30)$ subjects. Specifically, age $(60 \pm 2.1$ vs $56 \pm 3.3$ years, $p=\mathrm{NS}$ ), and sex distribution (male/female $=8 / 14$ vs $13 / 17, p=\mathrm{NS}$ ), did not differ among the groups. All study subjects were white. Fasting blood glucose $(8.8 \pm 0.4 \mathrm{vs} 4.7 \pm 0.3 \mathrm{mmol} / \mathrm{l}, p<0.001)$ and weight (body mass index $=27.4 \pm 0.6 \mathrm{vs} 25.0 \pm 1.0 \mathrm{~kg} / \mathrm{m}^{2}, p<0.05$ ), were higher among the Type 2 diabetic subjects compared with the non-diabetic control subjects. The values for serum total magnesium, serum Mg-io, and erythrocyte $\mathrm{Mgi}$ among the two patient groups are shown in Table 1. Intracellularly, Type 2 diabetes was uniformly associated with a significant suppression of free magnesium levels. This was true of all the subjects, with almost no overlap of data points between Type 2 diabetes and non-diabetic control subjects. In the extracellular circulation, serum Mg-io levels, but not serum total magnesium levels, were also significantly lower in Type 2 diabetic subjects, compared with non-diabetic control subjects. The individual serum $\mathrm{Mg}$-io values for control and diabetic subjects are displayed in Figure 1. For all subjects, a positive, significant relationship was observed between Mgi and extracellular serum Mg-io levels $(r=0.728, p<0.001)$, as shown in Figure 2. Serum total magnesium was also related to Mgi levels, albeit more weakly $(r=0.587, p<0.05)$.

\section{Discussion}

The almost universal involvement of magnesium biochemically in a wide variety of cellular processes critical to both cardiovascular function and glucose and insulin metabolism is well appreciated. Nevertheless, the existence

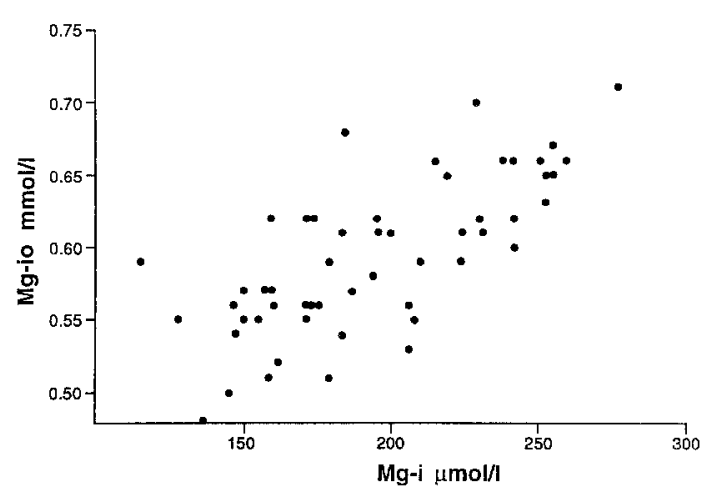

Fig. 2. Relation of serum ionized magnesium values ( $\mathrm{Mg}$-io) to intracellular levels of free magnesium. Mgi, intracellular free magnesium levels. $\mathrm{Mg}$-io and $\mathrm{Mgi}$ were significantly related, $r=0.728$, $(p<0.001)$ 
and role of magnesium deficiency in various human disease states remains unclear. There are at least two reasons for this. First, intracellularly, it was believed that magnesium could not be a regulatory factor at physiologically occurring concentrations, since magnesium levels measured by standard methods are in the millimolar range, far in excess of the regulatory, $\mathrm{K}_{\mathrm{m}}$-micromolar concentration range of most $\mathrm{Mg}$-dependent enzyme and ion pump mechanisms [18, 19]. Second, extracellularly, except for conditions inducing magnesium wasting, often iatrogenic, or in extreme presentations of more common diseases, such as diabetic ketoacidosis, serum $\mathrm{Mg}$ levels in e. g. hypertension, Type 2 diabetes, and other cardiovascular and metabolic diseases, have not been consistently measured outside the range considered normal.

The advent of new techniques to directly assess the ionic, freely available magnesium both intracellularly and in the circulation, have allowed us to investigate these issues more precisely. Our group has previously used ${ }^{31} \mathrm{P}$ NMR spectroscopy to study Mgi levels in normal human subjects, as well as in subjects with essential hypertension, obesity, and Type 2 diabetes $[11,12]$. Contrary to what had been suspected, Mgi exists in the regulatory concentration range (250-500 $\mathrm{mmol} / \mathrm{l})$ for most magnesium-dependent enzyme, channel, and pump mechanisms. This is true for cardiac muscle [20] and vascular smooth muscle [21], as well as for peripheral erythrocytes [12]. Furthermore, both essential hypertension and Type 2 diabetes are associated with significantly lower Mgi levels $[11,12]$. That these findings are clinically significant is suggested by the close, inverse relationships observed in essential hypertension, between Mgi, blood pressure [12] and the degree of insulin resistance [13]; and in Type 2 diabetes, between Mgi and the level of fasting blood glucose [11]. Similarly, and even more recently, an $\mathrm{Mg}$-selective ion electrode apparatus has been developed, which allows for a direct assessment of the free $\mathrm{Mg}$-io in the extracellular space [14]. Normal circulating levels of Mg-io appear to exist within a narrow range, as is true for the control non-diabetic subjects studied here.

This report not only confirms our previous findings of intracellular magnesium depletion in Type 2 diabetes, but demonstrates at the same time that serum $\mathrm{Mg}$-io levels are also significantly lower in diabetic, compared with nondiabetic control subjects, suggesting that in chronic stable Type 2 diabetes, depletion of extracellular magnesium occurs as well. This is further supported by the positive linkage we observed between Mgi levels and serum Mg-io measurements made in the same patient at the same time. Since obesity per se is not associated with significantly lower Mgi levels [11], it is doubtful that the differences reported here are due to the slightly increased body mass index of the Type 2 diabetic patients. Furthermore, our observed differences may actually underestimate those found in the general diabetic population, since our study subjects had only mild disease, with only minimal laboratory signs, and no symptoms of diabetes. Indeed, more than half of the Type 2 diabetic subjects studied here had not previously known of any abnormality of carbohydrate metabolism, and none had ever had any specific antidiabetic therapy.
These data suggest the overall notion that magnesium deficiency, defined on the basis of either Mgi levels or serum $\mathrm{Mg}$-io concentrations, is a common, if not universal feature of the diabetic state. This concept, if supported by further studies of larger populations, has clinically significant implications. Pathophysiologically, magnesium depletion can directly cause vasoconstriction and frank hypertension [22], can predispose to cardiac arrhythmias and sudden death $[10,23]$, can increase platelet aggregation and thus the potential for in situ thrombosis [24-26], and can produce the pathologic lesions of atherosclerosis [27], all the above occurring clinically to an increased extent in diabetes. Hence, the present data suggest that the cardiovascular consequences of diabetes may be at least partly due to deficient magnesium.

Regardless of the possible implications of these data, the simple technical requirements and improved precision of the serum $\mathrm{Mg}$-io measurement are certain to expand our clinical diagnostic capabilities. Its relevance to the diagnosis and clinical course of a variety of diseases is eagerly anticipated, once this selective ion electrode apparatus becomes more generally available.

Acknowledgements. We would like to especially thank Ms. C. Veneroni, Ms. L. Marra, and Ms. J. Francis for their extensive help in preparing and distributing blood samples to the different sites for analysis.

\section{References}

1. Aikawa J (1960) Effect of glucose and insulin on magnesium metabolism in rabbits. A study with magnesium-28. Proc Soc Exp Biol Med 103: 363-366

2. Atchley D, Loeb R, Richards D, Benedict E, Driscoll M (1933) On diabetic acidosis. A detailed study of electrolyte balances following the withdrawal and reestablishment of insulin therapy. J Clin Invest 12: 297-323

3. Nabarro J, Spencer A, Stowers J (1952) Metabolic studies in severe diabetic ketosis. Q J Med 21: 225-241

4. Rosner F, Gorfien $P$ (1970) Zinc and magnesium levels in diabetes. JAMA 211:2156

5. Stutzman F, Amatuzio D (1953) Blood serum magnesium in portal cirrhosis and diabetes mellitus. J Lab Clin Med 41:215

6. Becket A, Lewis J (1959) Serum magnesium in diabetes. Clin Sci 18: 597

7. Altura B, Halevy S, Turlaplaty P (1979) Vascular smooth muscle in diabetes and its influence on the reactivity of blood vessels. Adv Microcirc 8: 118-150

8. Altura B, Altura B (1981) Magnesium ions and contraction of vascular smooth muscles: relationship to some vascular diseases. Fed Proc 40: 2672-2679

9. Chadda K, Gupta P (1972) Magnesium in cardiac arrhythmias. N EnglJ Med 287: 1102

10. Kafka H, Langevin L, Armstrong P (1987) Serum magnesium and potassium in acute myocardial infarction: influence on ventricular arrhythmias. Arch Int Med 147:465-469

11. Resnick L, Gupta R, Bhargava K, Gruenspan H, Alderman M, Laragh $\mathrm{J}$ (1991) Cellular ions in hypertension, diabetes, and obesity: a nuclear magnetic resonance spectroscopic study. Hypertension 17: 951-957

12. Resnick L, Gupta RK, Laragh JH (1984) Intracellular free magnesium in erythrocytes of essential hypertension: relation to blood pressure and serum divalent cations. Proc Natl Acad Sci USA 81: 6511-6515

13. Resnick L, Gupta R, Gruenspan H, Alderman M, Laragh J (1990) Hypertension and peripheral insulin resistance: mediating role of intracellular free magnesium. Am J Hypert 3: 373-379 
14. Altura BT, Shirey TL, Hiti J, Tell'Orfano K, Hendwerker SM, Altura BM (1992) Characterization of a new ion selective electrode for ionized magnesium in whole blood, plasma, and serum. Methods Find Exp Clin Pharm 14:297-304

15. Resnick L, Altura B, Altura B, Gupta R, Laragh J (1992) Serum ionized magnesium in essential hypertension and non-insulin dependent diabetes mellitus: relation to intracellular free magnesium. Clin Res 40: 438 A (Abstract)

16. Resnick L (1989) Hypertension and abnormal glucose homeostasis: possible role of divalent ion metabolism. Am J Med 87 [Suppl 6A]: 17S-22S

17. Gupta R, Benovic J, Rose J (1978) The determination of the free magnesium level in the human red blood cell by ${ }^{31} \mathrm{P}-\mathrm{NMR}$. J Biol Chem 253: 6172-6176

18. Stephenson E, Podolsky R (1977) Regulation by magnesium of intracellular calcium movement in skinned muscle fibers. J Gen Physiol 69: 17-35

19. Flatman P, Lew V (1981) The magnesium dependence of sodium pump mediated sodium-potassium and sodium-sodium exchange in intact human red cells. J Physiol (Lond) 315: 421-446

20. Altura BM, Altura BT (1990) Magnesium and the cardiovascular system: experimental and clinical aspects updated. In: Sigel $\mathrm{H}$, Sigel A (eds) Metal ions in biological system, vol 26. Marcel Dekker, New York, pp 359-416

21. Zahng A, Cheng T, Altura BT, Altura BM (1992) Extracellular magnesium regulates intracellular free $\mathrm{Mg}^{2+}$ in vascular smooth muscle cells. Pfuegers Arch 421:391-393

22. Altura BM, Altura BT, Gebrewold A (1984) Magnesium deficiency and hypertension: correlation between magnesium-defi- cient diets and microcirculatory changes in situ. Science 223: $1315-1317$

23. Johnson C, Peterson D, Smith E (1979) Tissue concentrations of magnesium and potassium in men dying of suddenly with ischemic heart disease. Am J Clin Nutr 32: 967-970

24. Stevenson M, Yoder L (1970) Studies of platelet aggregation, plasma ADP breakdown and blood coagulation in $\mathrm{Mg}$ deficient calves and rats. Thromb Diathes Haemorrh 23:300-305

25. Nadler J, Malayan S, Luong H, Shaw S, Natarajan R, Rude R (1992) Evidence that intracellular free magnesium deficiency plays a key role in increased platelet reactivity in type II diabetes mellitus. Diabetes Care 15: 835-841

26. Huntsman R, Hurn B, Lehman H (1960) Observations on the effect of magnesium on blood coagulation. J Clin Pathol 13:99-101

27. Altura B, Brust M, Bloom S, Barbour R, Stempack J, Altura B (1990) Magnesium dietary intake modulates blood lipid levels and atherogenesis. Proc Natl Acad Sci USA 87: 1840-1844

Received: 18 December 1993

and in revised form: 29 March 1993

Dr. L. M. Resnick

Division of Endocrinology and Hypertension

Wayne State University Medical Center

University Health Center- $4 \mathrm{H}$

4201 St Antoine

Detroit, MI 48201

USA 